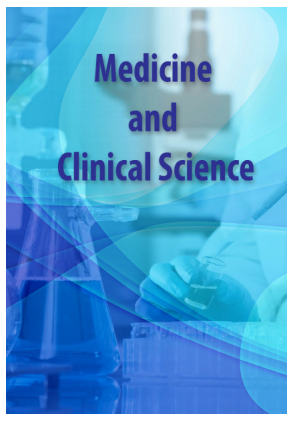

Correspondence

Dr. Christoforos Stylianides

Ophthalmologist, Agias Zonis 33, 3027, Limassol, Cyprus, Tel.: +35799577983

E-mail: christoforos_md@msn.com

- Received Date: 07 June 2020;

- Accepted Date: 15 June 2020;

- Publication Date: 24 June 2020.

\section{Keywords}

Secondary cataract; posterior capsule opacification; microincisional cataract surgery

\section{Copyright}

(c) 2020 Science Excel. This is an openaccess article distributed under the terms of the Creative Commons Attribution 4.0 International license.

\title{
Posterior capsule opacification (PCO) rate of a hydrophilic acrylic intraocular lens suitable for microincisional cataract surgery (MICS)
}

\author{
Stylianides Christoforos ${ }^{*}$, Höh Helmut and Ulrike Holland \\ Department of Ophthalmology, Dietrich Bonhoeffer Klinikum, Salvador-Allende-Straße 30, 17036 Neubrandenburg, Germany
}

\begin{abstract}
Purpose: To determine the capsulotomy rate of MICS-IOL (IntraOcular Lens) L-313 compared to other IOLs.

Setting:Department of Ophthalmology of the Dietrich Bonhoeffer Klinikum (DBK) in Neubrandenburg Germany, Teaching Hospital of the University Greifswald, Germany

Design: Monocentric, partly retrospective and partly prospective study

Method: Data from a total of 5.549 eyes implanted with MICS IOL LENTIS L-313 (OSD Medical GmbH, Berlin, Germany) during cataract surgery in our clinic between 9/2009 and 12/2013 were collected between $5 / 2013$ and 10/2017. It is registered at www.clinicaltrials.gov (NCT03184428).

The performance of a laser capsulotomy was evaluated as a criterion for the presence of a clinically relevant PCO. The statistical evaluation was carried out using Kaplan-Meier statistics with the program STATISTICA, Version 13 (StatSoft, Hamburg, Germany).

Results: The average patient age was 73.75 years \pm 9.06 (range 5 to 96 ) and $59.2 \%$ were female. The median follow-up period is 4.2 years. 4.224 data sets could be evaluated for patients over 54 years of age. The IOL L-313 PCO rate is $4.7 \%$ after 1 year, $8.2 \%$ after 2 years, $17.2 \%$ after 4 years and $22.4 \%$ after 6 years.

The L-313's PCO rate is low compared to other MICS lenses and two to three times higher compared to non-MICS lenses with a sharp optical edge. It is only half compared to that of (PMMA) lenses. Conclusions: The L-313 IOL's PCO rate is approximately twice to three times higher than non-MICS IOLs with a sharp optical edge but low compared to the PCO rate of other MICS-IOLs.
\end{abstract}

\section{Introduction}

By improving the surgical technique [1-10] and introducing modern intraocular lenses, the posterior capsule opacification (PCO) rate after posterior chamber lens implantation has been reduced. However, it still remains the most common postoperative complication of cataract surgery [11-24].

PCO formation leads to reduced visual acuity and increased glare sensitivity and ultimately requires a Nd: YAG laser capsulotomy. The PCO rate varies considerably depending on the IOL -material and -design [25-28]. MICS-IOLs (microincision cataract surgery intraocular lens) appear to have a higher PCO rate than non-MICS lenses [2981]. According to Menapace a lens is defined as a MICS lens if it can be implanted through a corneal incision $\leq 2 \mathrm{~mm}$ [82]. In this paper we use the term "non-MICS lens" to describe a IOL that is usually implanted through a wider incision.

The aim of this study is to determine the capsulotomy rate of the L-313 MICS-IOL (OSD Medical GmbH, Berlin) approved on the German market and to compare these results with the capsulotomy rates of other intraocular lenses (in particular with other MICS-IOLs) indicated in the literature.

\section{Patients and Methods}

\section{Intraocular Lens}

The LENTIS L-313 MICS lens (OSD Medical $\mathrm{GmbH}$, Berlin, Germany) is a foldable, hydrophilic, one-piece acrylic posterior chamber lens with a hydrophobic acting surface, sharp optic and haptic edge, an optical diameter of $6.0 \mathrm{~mm}$ and a total diameter of $11.0 \mathrm{~mm}$. The lens is implanted through a $1.8 \mathrm{~mm}$ diameter injector. We have been implanting this lens in our clinic since 2009 and, with over 7.000 implantations, have a sufficient amount of knowledge and experience to be able to make a representative statement about the postoperative $\mathrm{PCO}$ rate.

\section{Patients and surgical technique}

There was no co production of research within Patient and Public Involvement.

This study includes 5.549 eyes that were treated with the L-313 intraocular lens during cataract surgery at the Dietrich Bonhoeffer Hospital and Clinic in Neubrandenburg from September 2009 to December 2013. 
The patients were operated under retrobulbar anaesthesia, topical anaesthesia or intubation anaesthesia. Two corneal $1 \mathrm{~mm}$ paracenteses were created. The capsulorhexis was performed manually (continuous curvilinear capsulorhexis) under viscoelastic protection (predominantly methyl cellulose, Zeiss, Jena, Germany) with a target diameter of approx. $5.0 \mathrm{~mm}$. Then phacoemulsification and lens implantation were performed through a clear cornea incision. The incision was made on the steeper axis based on the pre-existing corneal astigmatism. The width of the incision was 1.8 $\mathrm{mm}$ (two such incisions) for biaxial phacoemulsification if corneal astigmatism was less than $0.5 \mathrm{dpt}, 2.2 \mathrm{~mm}$ if corneal astigmatism was up to $1.5 \mathrm{dpt}$ and up to $3.2 \mathrm{~mm}$ if corneal astigmatism was more than $1.5 \mathrm{dpt}$. The incision extension up to $3.2 \mathrm{~mm}$ was performed at the end of the cataract operation as an anti-astigmatic incision. Seven different surgeons performed the surgeries and used the Divide \& Conquer, Chip \& Flip and Phakochop techniques. The cortical residues were always extracted bimanually. Each surgeon used either the polishing curette, diamond polisher, aspiration cannula or water jet polishing to polish the posterior capsule. The rear surface of the front capsule was not polished. Then, either under irrigation or after filling the capsular bag with viscoelastic, the L-313 lenses were implanted into the capsular bag (using an injector with a diameter of $1.8 \mathrm{~mm}$ ). The corneal incisions and the paracenteses were then hydrated. Postoperatively, the patients received cortisone- and antibiotic-containing eye drops and ointments for about 4 weeks.

\section{Data collection and statistical analysis}

The data were planned to be collected from the database of the Dietrich Bonhoeffer Hospital and Clinic in Neubrandenburg by means of patient surveys, from the databases of the ophthalmologists providing follow-up treatment and eventually from an invitation of the patients to the Hospital. To save transportation costs patients that lived further than $50 \mathrm{~km}$ away from the hospital, were excluded.

The data was collected chronologically in four steps (the first retrospectively, the others prospectively):

First, all pre-, intra-, and postoperative data were retrospectively collected from patient files between May 2013 and March 2016, also with regard to whether a Nd:YAG-laser capsulotomy had already been performed. Neodymium-YAG capsulotomies already performed were recorded as uncensored cases with the Kaplan-Meier statistics and the patients without capsulotomy were censored with the last available follow-up date in our patient records.

Secondly, all patients with no current findings in their medical records were asked in filling out a standardised questionnaire whether and when a laser treatment of the PCO had been carried out in the meantime. The possible answers were "yes", "no" and "I'm not sure". This second study step was carried out prospectively after approval by the University of Greifswald's Ethics Committee.

Thirdly, if the answer was uncertain or unusable, or if the patient did not respond, a telephone consultation was carried out with the patient.

In a fourth step, if the answer was still uncertain or unusable, or if the patient did not provide any feedback, the post-treatment ophthalmologists were asked to provide information on the posterior capsule opacification (by phone, written inquiry or by visiting the practice).

It was not necessary to invite patients to our hospital for assessment, as intended in the study protocol, because all necessary data could be collected in the first four steps.

Data collection included age, gender, lens density, duration of surgery, phaco machine used, phaco energy, phaco time, surgeon, IOL refractive power, incision size, and the combination of cataract surgery with other procedures.

No data on general diseases or other eye diseases was collected because the literature does not contain any significant correlations to these diseases $[83,84]$. For medical reasons, eyes in which a posterior capsule rupture had occurred intraoperatively were excluded.
If patients had undergone cataract surgery on both sides, both eyes were included in the database if there were no reasons for exclusion.

The statistical evaluation of the collected data was carried out with the program STATISTICA, version 13 (StatSoft, Hamburg, Germany) with the Kaplan-Meier analysis. For the correlation tests, the Spearman-Rank correlation test was used and a Bonferroni adjustment was made during test repetition.

Given that in the literature children and young adults have a higher and faster PCO development $[85,86]$, the statistical evaluations for the group under 55 and the group from 55 or older were carried out separately.

To compare the PCO rates we collected with those of other MICS and conventional (non-MICS) intra-ocular lenses, publications were selected that used the Nd:YAG laser capsulotomy frequency as a criterion for the PCO formation [29-81]. Studies whose PCO criterion is based on other methods, such as the evaluation of retroillumination images, are not taken into account due to lack of comparability [87123]

Some of the comparative publications have significantly shorter follow-up periods than our work. However, the follow-up period has a considerable influence on the PCO rate. We have taken the corresponding PCO rate from our Kaplan-Meier curve for the respective average follow-up time of each individual foreign publication.

\section{Results}

During the study period, a total of 5.549 eyes (women $59.2 \%$, men $40.8 \%$ ) received a LENTIS L-313 intraocular lens during cataract surgery. The average age of the patients was $73.75 \pm 9.06$ years (range 5 to 96 years).

A total of 952 eyes were excluded from the study (see exclusion criteria in the method section): 20 eyes (intraoperative posterior capsule rupture), 924 eyes (more than $50 \mathrm{~km}$ away), 8 eyes (lens exchange).

No follow-up findings were available for 209 eyes: 13 eyes (closure of post-treatment ophthalmologist's practice), 64 eyes (lack of patient consent to the study), 131 eyes (not available in any general practitioner system), 1 eye (no follow-up). This leaves 4.388 eyes for evaluation.

The data on the 4.388 eyes were collected as follows: 155 eyes from our patient records, 1.356 eyes by mail from the patients, 1.397 eyes from phone calls with the patients, 1.480 eyes from the patient records of the licensed ophthalmologists.

Figure 1 shows the age distribution on the day of surgery. The average follow-up period is $\mathrm{m}=1.480$ days (corresponding to 49.3 months or 4.1 years). The median is 1.527 days (corresponding to 50.9 months or 4.2 years). We classify the lens density on a scale from 0 (soft) to 4 (very hard). The average was $1.77(\mathrm{n}=3.944)$. The duration of the operation was documented in minutes. It averaged 14.0 min $(n=4.068)$. Seven phaco machines $(n=3.906)$ were used for phacoemulsification: Millennium (Bausch \& Lomb, Rochester, NY, USA): 2.322 eyes, Geuder Megatron (Geuder AG, Heidelberg, Germany): 1.091 eyes, EVA (DORC, Zuidland, the Netherlands): 93 eyes, Stellaris (Bausch \& Lomb, Rochester, NY, USA): 13 eyes, OERTLI (Oertli Instrumente AG, Berneck, Switzerland): 301 eyes, Zeiss Visalis (Zeiss, Oberkochen, Germany): 53 eyes, Constellation (ALCON, Fort Worth, TX, USA): 33 eyes. The phaco energy was documented in $\%$ of the power. It averaged $31.9 \%(\mathrm{n}=3.864)$ and the effective phaco time was documented in seconds. It averaged 9.7 $\mathrm{s}(\mathrm{n}=4.088)$. Seven surgeons performed the cataract operations $(\mathrm{n}$ = 4.049): HH: 29 eyes, SE: 1.367 eyes, VE: 1.397 eyes, HA: 253 eyes, DRA: 565 eyes, WE 278 eyes, WEI: 69 eyes. The IOL refractive power was documented in diopters. It averaged $21.2 \mathrm{dpt}(\mathrm{n}=4.224)$.

The incision size was divided into two groups. 3.649 of 4.224 eyes, were operated through a 1.8 or $2.2 \mathrm{~mm}$ incision and 575 eyes through a $3.2 \mathrm{~mm}$ incision. In 127 eyes cataract surgery was performed in combination with other procedures (e.g. vitrectomy or glaucoma surgery) and in 3.831 eyes a pure cataract surgery was performed. 


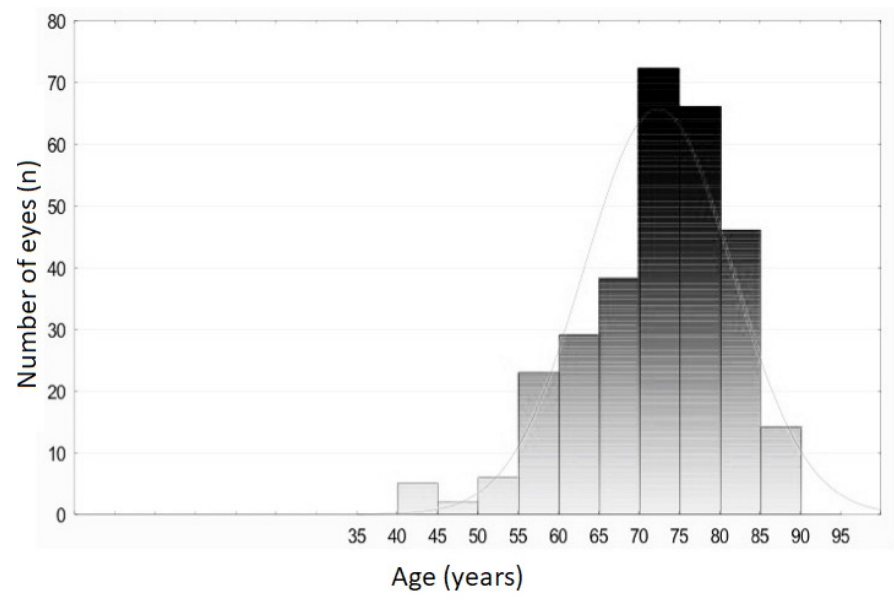

Figure 1: Age distribution of patients on the day of surgery $(\mathrm{n}=4.388)$. The width of the age columns is five years and ranges, for example, from 45 to 49 years and so on.

Figure 2A shows the capsulotomy rate of IOL L-313 in patients younger than $55(\mathrm{n}=164)$. Two time periods can be distinguished in this curve. In the first phase, the capsulotomy rate evolves almost linearly (7\% per year) and relatively steeply over time. In the second phase (after approx. 4 years) a plateau appears to form (PCO development $2 \%$ per year).

Figure 2B shows the capsulotomy rate of IOL L-313 in $\geq 55$ year-old patients $(\mathrm{n}=4.224)$. The capsulotomy rate or PCO rate for these patients is $4.7 \%$ after 1 year, $8.2 \%$ after 2 years, $17.2 \%$ after 4 years and $22.4 \%$ after 6 years. In this curve, these two periods cannot be distinguished as clearly as in the younger patients. In the first 4 years, the PCO rate evolves at $3.5 \%$ per year. After the fourth year, this evolution is reduced to $2.6 \%$ per year.

The average capsulotomy rate was $10.4 \%$ and the average time (from day of surgery to day of capsulotomy) was 899.0 days (30.0 months). The median was a $9.6 \%$ capsulotomy rate after a median of 829 days (27.6 months)

To compare the PCO rates we collected with those of other MICS and non-MICS intraocular lenses, we have taken into consideration publications that also used the Nd:YAG laser capsulotomy frequency as a criterion for PCO formation [29-73, A-H]. The PCO rate correlates with patient and intraoperative data as follows (SpearmanRank correlation):

Significant correlations (in eleven test repetitions a $p<0.0045$ is required after Bonferroni adjustment for a statistically significant correlation with a probability of error of $<5 \%)$ : PCO rate to age $(\mathrm{r}$ $=-0.87, \mathrm{n}=4,388, \mathrm{p}=0.0001), \mathrm{PCO}$ rate to combined procedure $(\mathrm{r}=$ $0.05, \mathrm{n}=4.224, \mathrm{p}=0.002$ )

No significant correlations were found after Bonferroni adjustment of PCO rate to gender, lens density, operation duration, phaco machine, phaco energy, phaco time, surgeon, IOL refractive power and incision size.

\section{Discussion}

Posterior capsule opacification is the most common complication of cataract surgery in the postoperative process. A Nd:YAG laser capsulotomy is necessary when postoperative vision is impaired by the development of posterior capsule opacification. We have defined the laser treatment of a "clinically relevant" posterior capsule opacification as a measure for our analysis. Compared to evaluating retroillumination images, this parameter has the advantage that it takes into account the influence of the posterior capsule opacification on visual acuity. The posterior capsule opacification is only clinically relevant if it affects the visual acuity and we assume that in that case it was treated with Nd:YAG laser capsulotomy. The influence on visual acuity cannot be derived directly from pure area measurements of the posterior capsule opacification areas in retroillumination images.
In contrast to the evaluation of retroillumination images, the comparative evaluation using the Nd:YAG laser frequency requires a significantly longer follow-up time in order to achieve valid results. This prerequisite here is a maximum follow-up time of more than 6 years and a median follow-up time of 4.6 years.

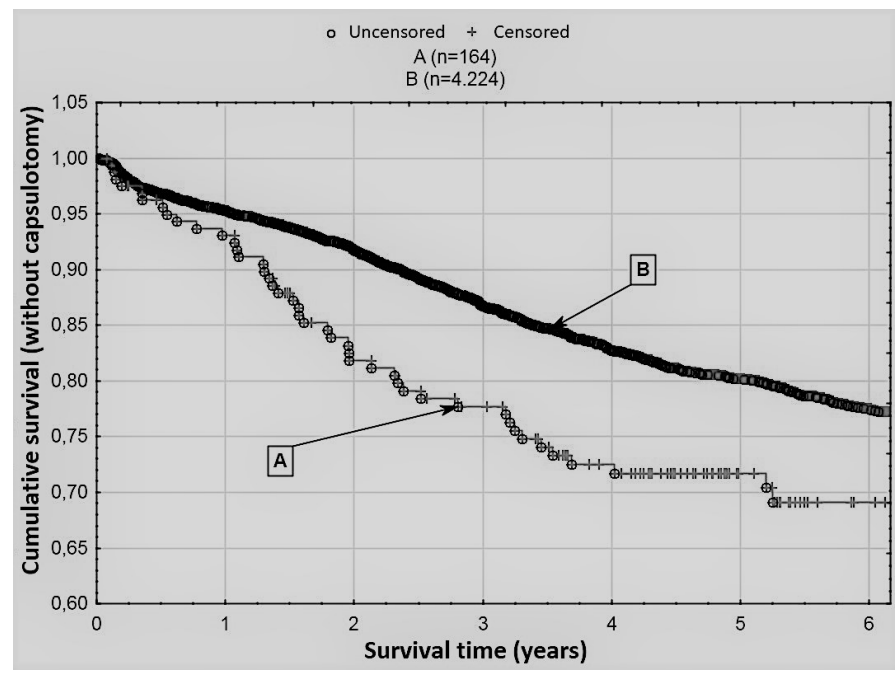

Figure 2: A: Kaplan-Meier curve of the PCO rate after L-313 implantation of patients younger than $55(\mathrm{n}=164)$. The rate of PCO development from the first to the fourth postoperative year is 7\% per year, followed by a plateau with an average PCO development of $2 \%$ per year.

B: Kaplan-Meier curve of PCO rate after L-313 implantation of patients older than $54(\mathrm{n}=4.224)$. The average speed of PCO development from the first to the fourth postoperative year is 3.5\% per year and then flattens out with an average PCO development of $2.6 \%$ per year.

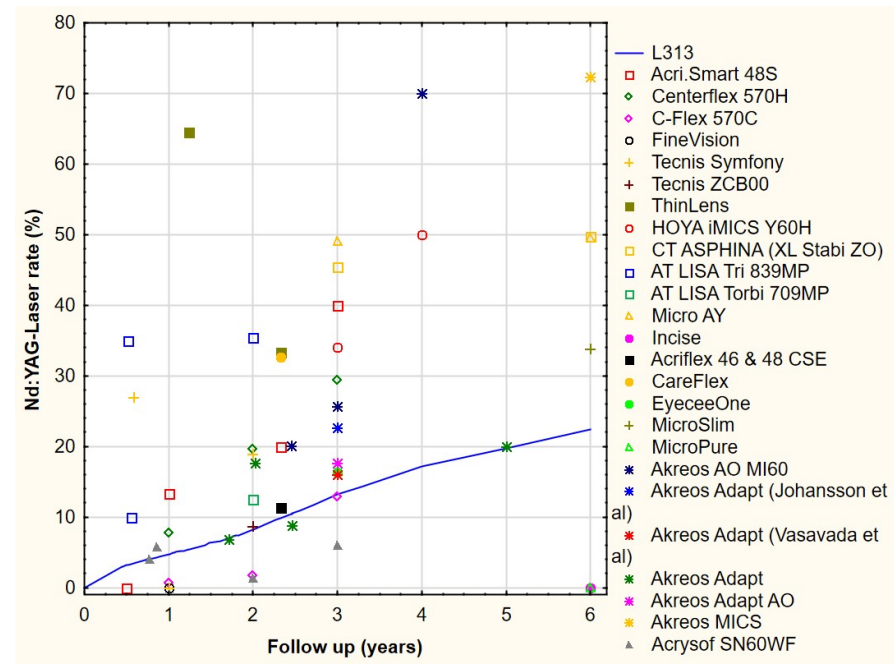

Figure 3: The L-313's capsulotomy rate is indicated by a blue line for up to 6 years in each case. The publications on the reference lenses are given as data points with the capsulotomy rate and follow-up time (see legend in the figure for coding). The majority of comparison lenses have a higher capsulotomy rate than the L-313. 
To compare the posterior capsule opacification frequency of the LENTIS L-313 IOL (OSD Medical GmbH, Berlin, Germany) with other intraocular lenses, we have used publications that also used Nd:YAG capsulotomy as a criterion for posterior capsule opacification development [29-81].

\section{Comparison with MICS lenses (Figure 3):}

Three groups can be distinguished within the MICS lenses, depending on the PCO rate.

The lenses in the first group have a very low PCO rate of zero percent, e.g. the Acri.Smart 48S (Acri.Tec ${ }^{\oplus}$, Hennigsdorf, Germany) after 6 months [29], FineVision (Physiol SA, Liege, Belgium) after 1 year58 and Incise (Bausch \& Lomb, Rochester, NY, USA) and MicroPure (PhysIOL, Liege, Belgium) 6 years postoperatively [77]. After 850 days, the Acri.Smart 48S PCO rate is $20.0 \%$ [64]. The data set in the work of Ruiz-Mesa et al [58] is quite small $(n=40)$. We are not aware of the method used to determine the PCO rate in the work of Lesieur et al. [77] with regard to Incise and MicroPure.

In the second group are the MICS lenses with a low capsulotomy rate but comparable to that of L-313, C-Flex 570C (Rayner, London, UK) [48,71], AT LISA Torbi 709MP (Zeiss, Jena, Germany) [78], Akreos Adapt and Akreos Adapt AO (Bausch \& Lomb, Rochester, NY, USA) [71,75], EyeceeOne (Bausch \& Lomb, Rochester, NY, USA) [46], the Tecnis ZCB00 (AMO, Santa Ana, CA, USA) [78] and Acrysof SN60WF (ALCON, Fort Worth, TX, USA) $[31,46,52,63]$. This group also includes Acriflex 46 and 48 CSE (Acrimed GmbH, Berlin, Germany). According to the work of Spyridaki et al (Figure 3), the PCO rate of the AcriFlex $46 \& 48$ CSE is $11.4 \%$. This puts the L-313 at 9.8\%, similar to the Acriflex. The similarity of the PCO rates of these two IOLs (L313 and AcriFlex) was to be expected because the AcriFlex 46 is the L-313's predecessor. The comparability of these two IOLs' PCO rates also confirms the validity of our comparison method, including the back calculation to the comparative publication's follow-up period. All these lenses have a sharp optic edge.

The third group consists of lenses with a higher capsulotomy rate than L-313. This group comprises Centerflex $570 \mathrm{H}$ (Rayner, London, UK) [30], ThinLens (Thinoptx Inc., Virginia, USA) [55,64], Hoya iMICS Y60H (HOYA, Tokyo, Japan) [60,61], CT ASPHINA, previously known as XL Stabi ZO, (Zeiss, Jena, Germany) [32,75,77], AT LISA Tri 839MP (Zeiss, Jena, Germany) [74], Micro AY IOL (PhysIOL, Liege, Belgium) [60,77], CareFlex (w2o Medizintechnik AG, Bruchsal, Germany) [64], Akreos AO MI-60 and Akreos MICS (Bausch \& Lomb, Rochester, NY, USA) [71,80,81] and MicroSlim (PhysIOL, Liege, Belgium) [77] and Tecnis Symfony (AMO, Santa Ana, CA, USA) [58,74]. All these lenses except the Tecnis Symfony (AMO, Santa Ana, CA, USA) are made of hydrophilic acrylate. The ThinLens (Thinoptx Inc., Virginia, USA) and the Tecnis Symfony (AMO, Santa Ana, CA, USA) do not have a sharp optic edge, which we consider to be the most likely cause of the very high PCO rate.

Comparison with non-MICS lenses made of hydrophobic acrylate (Figure 4)

3 groups can be distinguished according to the PCO rate.

The lenses in the first group have a very low PCO rate. This group includes the Acrysof MA60BM, MA60AC, SA30AL, SN60WF (ALCON, Fort Worth, TX, USA) $[22,40,46,49,52,53,57,71-73,79,80]$ and HOYA PY60AD (HOYA (Tokyo, Japan) [52]. All these lenses have a sharp optic edge.

The second group includes lenses with a capsulotomy rate comparable to that of L-313. This group includes the older model of the HOYA lenses with round optical edges, FY60AD (HOYA, Tokyo, Japan) [52], as well as Acrysof MA30, MA30BA, SA60AT, SN60D3 (ALCON, Fort Worth, TX, USA) $[32,37,42,49,73,78]$, the Tecnis ZA9003 (AMO, Santa Ana, CA, USA) [78] and AR40e (AMO Inc., Santa ANA, CA, USA) with a sharp optic edge $[32,43]$.

The third group consists of lenses with a higher capsulotomy rate than L-313. This group includes VA-60BB (HOYA, Tokyo, Japan) with an incomplete sharp optic edge [53], AR40 (AMO Inc., Santa ANA, CA,
USA) with a round optic edge [43]. Almost all lenses in the first two groups have a sharp optic edge, while none in the third group do. One exception is the HOYA lens (the FY60AD is in the second group despite its round edge). However, in the work of Morgan-Warren [52] HOYA FY60AD (round optic edge) has twice the PCO rate of the HOYA PY60AD (sharp edge).

Comparison with non-MICS silicone lenses (Figure 5)

3 groups can also be distinguished.

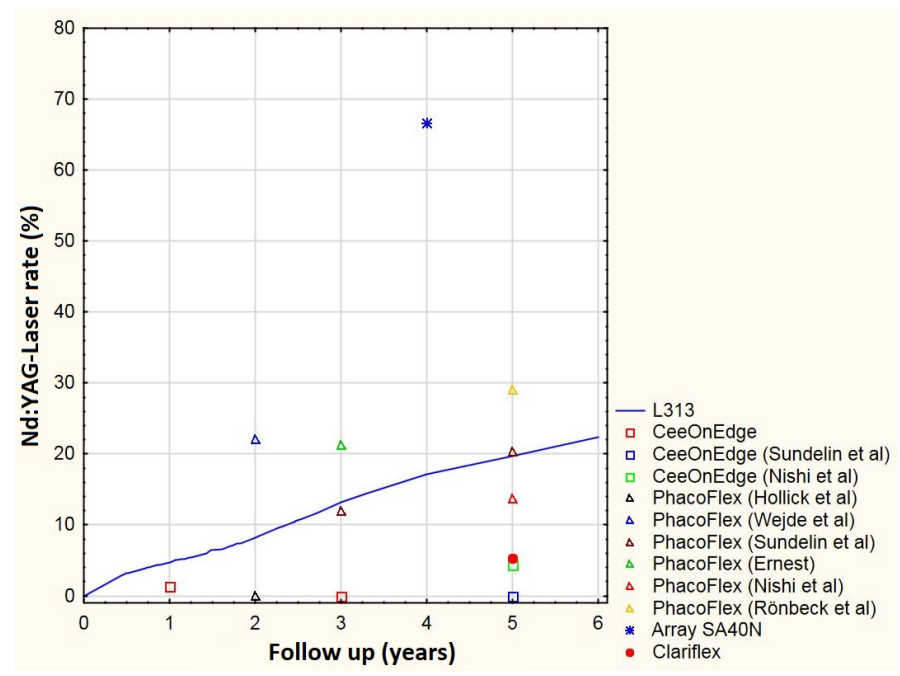

Figure 4: Comparison of L-313 IOL PCO rate with nonMICS hydrophobic acrylate lenses. The L-313's capsulotomy rate is indicated by a blue line up to 6 years. The publications

on the reference lenses are given as data points with the capsulotomy rate and follow-up time (see legend in the figure for coding). The y-scaling deviates here, so that the results and fine differences of the different IOLs should be clearly visible. The majority of comparison lenses have a capsulotomy rate comparable to or lower than the L-313.

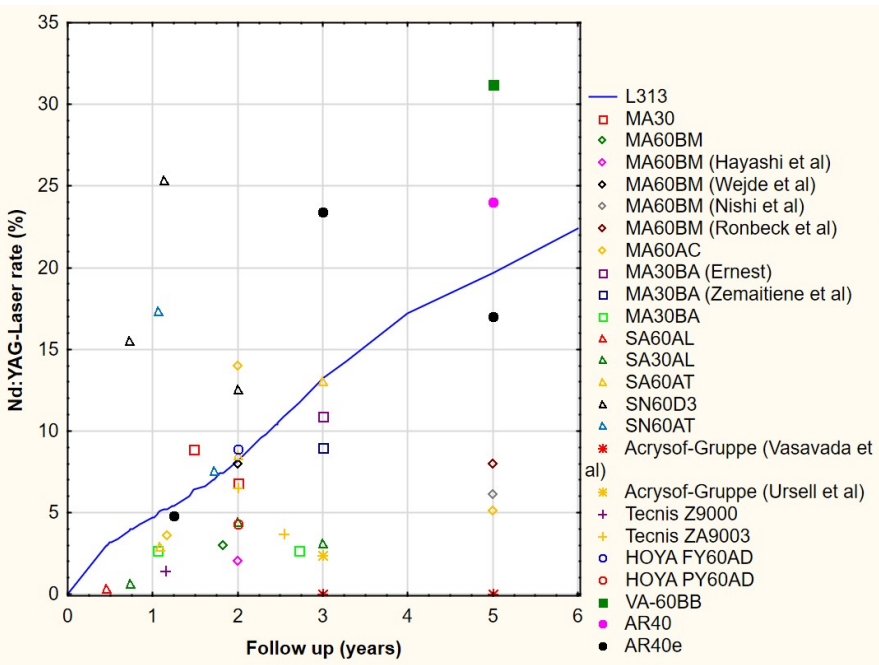

Figure 5: Comparison of the L-313 IOL PCO rate with non-MICS silicone lenses. The L-313's capsulotomy rate is indicated by a blue line up to 6 years. The publications on the reference lenses are given as data points with the capsulotomy rate and follow-up time (see legend in the figure for coding). The majority of comparison lenses have a capsulotomy rate comparable to or lower than the L-313. 
The lenses in the first group have a very low PCO rate. This group includes CeeOnEdge (AMO, Santa Ana, CA, USA) $[48,59,73]$ and Clariflex (AMO, Santa Ana, CA, USA) [53]. They are three-piece silicone lenses with a sharp optic edge.

The lenses in the second group have a capsulotomy rate comparable to L-313. This group includes PhacoFlex lenses (Allergan, Irvine, CA, USA), SI-30 and SI-40NB $[41,53,57,68,64]$. An exception is the work of Hollick et al [41] with low case numbers $(n=30)$. They are threepiece silicone lenses with a round optic edge.

The third group consists of lenses with a higher capsulotomy rate than L-313. This group includes Array SA40N, (AMO, Santa Ana, CA, USA), a three-piece silicone lens also without a sharp edge [38].

Again, it can be seen that all lenses in the first group have a sharp optic edge and those in the other two groups with the higher PCO rate have none.

Comparison with non-MICS lenses made of hydrophilic acrylate or PMMA (Figure 6)

2 groups can be distinguished.

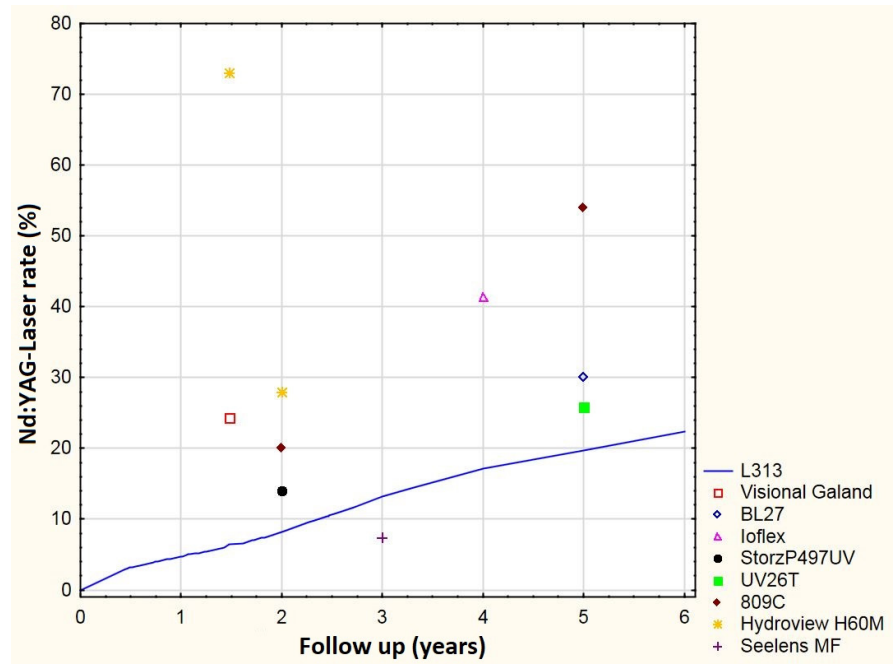

Figure 6: Comparison of L-313 IOL PCO rate with hydrophilic acrylate non-MICS lenses or PMMA lenses. The L-313's capsulotomy rate is indicated by a blue line up to 6 years. The publications on the reference lenses are given as data points with the capsulotomy rate and follow-up time (see legend in the figure for coding). The majority of the comparison lenses have a capsulotomy rate higher than the L-313.

The lenses in the first group have a lower PCO rate than the L-313. This group includes Seelens MF (Hanita Lenses, Israel), a one-piece hydrophilic acrylic lens with a sharp edge [76].

The second group consists of lenses with a significantly higher capsulotomy rate than the L-313. This group includes Hydroview H60M (Bausch \& Lomb, Rochester, New Jersey, USA) [40,41,59], Visional Galand lens (Société médicale de précision, Genf, Switzerland) [42], BL27 (Bausch \& Lomb, Rochester, NY, USA) [43], Ioflex lens (Mediphacos, Belo Horizonte, Brazil) [44], Storz P497UV (Storz, St. Louis, MO, USA) [41], die UV26T (Menicon, Nagoya, Japan) [53] and 809C (Pharmacia, Uppsala, Sweden) [57,64] .

Comparisons of PCO rates confirm the known fact that the IOL material (silicone $<$ hydrophobic $<$ hydrophilic and PMMA) and the IOL design (sharp optic edge $<$ incomplete sharp edge $<$ round edge) play an important role in PCO formation.

We were able to demonstrate a statistically significant correlation between age and PCO rate $(\mathrm{p}=0.0001)$. This statistically significant correlation is also demonstrated by Eballé et al [85]. The PCO rate decreases slightly with age. Combined procedures have a significantly higher PCO rate $(\mathrm{p}=0.002)$ than pure cataract operations. This statistically significant correlation is also demonstrated by Jun et al [124]. There was no significant correlation $(p>0.05)$ between gender, duration of surgery, phaco machine, phaco energy, phaco time, IOL refractive power, incision size and surgeon. Menapace et al [125], Gonzalez et al [83], Westling et al [126], Hashemi et al [127], and Svancarova et al [128] were also unable to demonstrate statistically significant correlations to these OP data.

After Bonferroni adjustment, we were unable to demonstrate a significant correlation between lens density and PCO rate ( $p>0.0045)$.

In summary, the L-313 has a comparable or lower capsulotomy rate compared to other MICS-IOLs. Compared to non-MICS IOLs with a sharp edge, the L-313 PCO rate is comparable for some lenses and two to three times higher for others. The cataract surgeon is not guided solely by the criterion of risk of posterior capsule opacification when selecting an IOL. Other factors such as the required incision size, IOL power range, optic and haptic design, material, availability of injectors, intraoperative handling, asphericity, postoperative stability in the capsular bag and, of course, postoperative patient satisfaction are also of great importance. However, the knowledge of the PCO risk is also required for selection. We want to contribute to this with this work.

\section{Clinical Trial Registry: NCT03184428 Acknowledgements}

We would like to thank OSD Medical GmbH (Berlin, Germany) for financing the study costs (Ethics Committee vote, data collection, postage costs and fee to the ophthalmologists for the data transfer).

$\mathrm{HH}$ receives financial support for this and other research projects from the sponsor OSD Medical GmbH (Berlin, Germany).

Presented at the XXXIV Congress of the ESCRS (Copenhagen 2016)

\section{References}

1. Auffarth GU, Brezin A, Caporossi A, et al. Comparison of Nd : YAG capsulotomy rates following phacoemulsification with implantation of PMMA, silicone, or acrylic intra-ocular lenses in four European countries. Ophthalmic Epidemiol. 2004;11(4):319-329.

2. Bao X, Hou M, Qin Y, Luo F, Shang F, Wu M. Effect of an MG132Sustained Drug Delivery Capsular Ring on the Inhibition of Posterior Capsule Opacification in a Rabbit Model. J Ocul Pharmacol Ther. 2017;33(2):103-110.

3. D'Eliseo D, Pastena B, Longanesi L, Grisanti F, Negrini V. Prevention of posterior capsule opacification using capsular tension ring for zonular defects in cataract surgery. Eur J Ophthalmol. 2003;13(2):151-154.

4. Lei M, Peng Z, Dong Q, et al. A novel capsular tension ring as local sustained-release carrier for preventing posterior capsule opacification. Biomaterials. 2016;89:148-156.

5. LiJH, Dong Z, Wang NL. [Experimental study on effects of matrix metalloproteinase inhibitor on posterior capsule opacification in rabbits]. Zhonghua Yan Ke Za Zhi. 2011;47(4):314-319.

6. Pallikaris IG, Stojanovic NR, Ginis HS. A new endocapsular open ring for prevention of anterior and posterior capsule opacification. Clin Ophthalmol. 2016;10:2205-2212.

7. Pandey SK, Apple DJ, Werner L, Maloof AJ, Milverton EJ. Posterior capsule opacification: a review of the aetiopathogenesis, experimental and clinical studies and factors for prevention. Indian J Ophthalmol. 2004;52(2):99-112.

8. Smith SR, Daynes T, Hinckley M, Wallin TR, Olson RJ. The effect of lens edge design versus anterior capsule overlap on posterior capsule opacification. Am J Ophthalmol. 2004;138(4):521-526.

9. Wang WY, Zhang ZJ, Wang J, Wang HW. An experimental study on the effects of curcumin on posterior capsule opacification in 
young rabbit eyes. Chin Med J (Engl). 2011;124(21):3527-3531.

10. Lutz EA, Gemensky-Metzler AJ, Wilkie DA, Chandler HL. Effects of pulsed fluid lens capsule washing following phacoemulsification on lens epithelial cells and posterior capsule opacification formation ex vivo. Vet Ophthalmol. 2015;18(3):221-228.

11. Apple DJ, Peng Q, Visessook N, et al. Eradication of posterior capsule opacification: documentation of a marked decrease in Nd:YAG laser posterior capsulotomy rates noted in an analysis of 5416 pseudophakic human eyes obtained postmortem. Ophthalmology. 2001;108(3):505-518.

12. Apple DJ, Peng Q, Visessook N, et al. Surgical prevention of posterior capsule opacification. Part 1: Progress in eliminating this complication of cataract surgery. J Cataract Refract Surg. 2000;26(2):180-187.

13. Chitkara DK, Smerdon DL. Risk factors, complications, and results in extracapsular cataract extraction. J Cataract Refract Surg. 1997;23(4):570-574.

14. Meacock WR, Spalton DJ, Boyce JF, Jose RM. Effect of optic size on posterior capsule opacification: $5.5 \mathrm{~mm}$ versus 6.0 $\mathrm{mm}$ AcrySof intraocular lenses. J Cataract Refract Surg. 2001;27(8):1194-1198.

15. Menapace R. [After-cataract following intraocular lens implantation. Part I. Genesis and prevention by optimizing conventional lens implants and surgical techniques]. Ophthalmologe. 2007;104(3):253-262; quiz 263-254.

16. Menapace R. [After-cataract following intraocular lens implantation. Part II: prevention with alternative implants and techniques]. Ophthalmologe. 2007;104(4):345-353; quiz 354345.

17. Mester U, Fabian E, Gerl R, et al. Posterior capsule opacification after implantation of CeeOn Edge 911A, PhacoFlex SI-40NB, and AcrySof MA60BM lenses: one-year results of an intraindividual comparison multicenter study. J Cataract Refract Surg. 2004;30(5):978-985.

18. Prosdocimo G, Tassinari G, Sala M, et al. Posterior capsule opacification after phacoemulsification: silicone CeeOn Edge versus acrylate AcrySof intraocular lens. J Cataract Refract Surg. 2003;29(8):1551-1555.

19. Schaumberg DA, Dana MR, Christen WG, Glynn RJ. A systematic overview of the incidence of posterior capsule opacification. Ophthalmology. 1998;105(7):1213-1221.

20. Schmidbauer JM, Vargas LG, Apple DJ, et al. [Millenniums update on posterior capsule opacification (PCO) scores, centration, biocompatibility and fixation of foldable intraocular lenses (IOL) - an analysis of 1,221 pseudophakic post mortem globes]. Klin Monbl Augenheilkd. 2001;218(10):649-657.

21. Tetz MR, Nimsgern C. Posterior capsule opacification. Part 2: Clinical findings. J Cataract Refract Surg. 1999;25(12):16621674.

22. Ursell PG, Spalton DJ, Pande MV, et al. Relationship between intraocular lens biomaterials and posterior capsule opacification. J Cataract Refract Surg. 1998;24(3):352-360.

23. Wehner W. [Microincision intraocular lens with plate haptic design. Evaluation of rotational stability and centering of a microincision intraocular lens with plate haptic design in 1219 months of follow-up]. Ophthalmologe. 2007;104(5):393-394, 396-398.

24. Milazzo S, Grenot M, Benzerroug M. [Posterior capsule opacification]. J Fr Ophtalmol. 2014;37(10):825-830.

25. Li Y, Wang J, Chen Z, Tang X. Effect of hydrophobic acrylic versus hydrophilic acrylic intraocular lens on posterior capsule opacification: meta-analysis. PLoS One. 2013;8(11):e77864.

26. Nishi O. [Influence of intraocular lens material and design on the development of posterior capsule opacification]. Ophthalmologe. 2005;102(6):572-578.

27. Ronbeck M, Kugelberg M. Posterior capsule opacification with 3 intraocular lenses: 12-year prospective study. J Cataract Refract Surg. 2014;40(1):70-76.

28. Zhang Z, Zheng D, Lin Y, Yang H, Lei S. [A clinical study of posterior capsular opacification after implantation of foldable intraocular lenses with different edges of optics]. Zhonghua Yan Ke Za Zhi. 2002;38(10):606-609.

29. Alio JL, Rodriguez-Prats JL, Vianello A, Galal A. Visual outcome of microincision cataract surgery with implantation of an Acri. Smart lens. J Cataract Refract Surg. 2005;31(8):1549-1556.

30. Becker KA, Martin M, Rabsilber TM, Entz BB, Reuland AJ, Auffarth GU. Prospective, non-randomised, long term clinical evaluation of a foldable hydrophilic single piece intraocular lens: results of the Centerflex FDA study. Br J Ophthalmol. 2006;90(8):971-974.

31. Biber JM, Sandoval HP, Trivedi RH, de Castro LE, French JW, Solomon KD. Comparison of theincidenceand visual significance of posterior capsule opacification between multifocal spherical, monofocal spherical, and monofocal aspheric intraocular lenses. J Cataract Refract Surg. 2009;35(7):1234-1238.

32. Boureau C, Lafuma A, Jeanbat V, Berdeaux G, Smith AF. Incidence of Nd:YAG laser capsulotomies after cataract surgery: comparison of 3 square-edged lenses of different composition. Can J Ophthalmol. 2009;44(2):165-170.

33. Cullin F, Busch T, Lundstrom M. Economic considerations related to choice of intraocular lens (IOL) and posterior capsule opacification frequency - a comparison of three different IOLs. Acta Ophthalmol. 2014;92(2):179-183.

34. Dada T, Sharma N, Dada VK, Vajpayee RB. Comparative evaluation of plate haptic lenses with smaller and larger positioning holes. Aust N Z J Ophthalmol. 1999;27(6):417-419.

35. Davison JA. Clinical performance of Alcon SA30AL and SA60AT single-piece acrylic intraocular lenses. J Cataract Refract Surg. 2002;28(7):1112-1123.

36. Duman R, Karel F, Ozyol P, Ates C. Effect of four different intraocular lenses on posterior capsule opacification. Int J Ophthalmol. 2015;8(1):118-121.

37. Ernest PH. Posterior capsule opacification and neodymium: YAG capsulotomy rates with AcrySof acrylic and PhacoFlex II silicone intraocular lenses. J Cataract Refract Surg. 2003;29(8):1546-1550.

38. Fujimoto K, Honda K, Wada YR, Tanaka M, Irie T. Four-year experience with a silicone refractive multifocal intraocular lens. J Cataract Refract Surg. 2010;36(8):1330-1335.

39. Ganesh S, Brar S, Pawar A. Long-term visual outcomes and patient satisfaction following bilateral implantation of trifocal intraocular lenses. Clin Ophthalmol. 2017;11:1453-1459.

40. Hayashi K, Hayashi H. Posterior capsule opacification after implantation of a hydrogel intraocular lens. Br J Ophthalmol. 2004;88(2):182-185.

41. Hollick EJ, Spalton DJ, Ursell PG, Meacock WR, Barman SA, Boyce JF. Posterior capsular opacification with hydrogel, 
polymethylmethacrylate, and silicone intraocular lenses: twoyear results of a randomized prospective trial. Am J Ophthalmol. 2000;129(5):577-584.

42. Javdani SM, Huygens MM, Callebaut F. Neodymium: YAG capsulotomy rates after phacoemulsification with hydrophobic and hydrophilic acrylic intraocular lenses. Bull Soc Belge Ophtalmol. 2002(283):13-17.

43. Johansson B. Clinical consequences of acrylic intraocular lens material and design: Nd:YAG-laser capsulotomy rates in $3 \mathrm{x}$ 300 eyes 5 years after phacoemulsification. Br J Ophthalmol. 2010;94(4):450-455.

44. Jorge Pde A, Jorge D, Ventura CV, et al. Incidence of posterior capsule opacification following the implantation of a foldable hydrophilic acrylic intraocular lens: a 4 year follow-up study. Arq Bras Oftalmol. 2014;77(4):222-224.

45. Khandwala MA, Marjanovic B, Kotagiri AK, Teimory M. Rate of posterior capsule opacification in eyes with the Akreos intraocular lens. J Cataract Refract Surg. 2007;33(8):1409-1413.

46. Leydolt C, Schartmuller D, Schwarzenbacher L, Schranz M, Schriefl S, Menapace R. Comparison of posterior capsule opacification development with 2 single-piece intraocular lens types. J Cataract Refract Surg. 2017;43(6):774-780.

47. Mamalis N, Phillips B, Kopp CH, Crandall AS, Olson RJ. Neodymium: YAG capsulotomy rates after phacoemulsification with silicone posterior chamber intraocular lenses. J Cataract Refract Surg. 1996;22 Suppl 2:1296-1302.

48. Mathew RG, Coombes AG. Reduction of Nd:YAG capsulotomy rates after implantation of a single-piece acrylic hydrophilic intraocular lens with 360 degrees squared optic edge: 24 -month results. Ophthalmic Surg Lasers Imaging. 2010;41(6):651-655.

49. Mian SI, Fahim K, Marcovitch A, Gada H, Musch DC, Sugar A. Nd:YAG capsulotomy rates after use of the AcrySof acrylic three piece and one piece intraocular lenses. Br J Ophthalmol. 2005;89(11):1453-1457.

50. Milauskas AT. Posterior capsule opacification after silicone lens implantation and its management. J Cataract Refract Surg. 1987;13(6):644-648.

51. Milazzo S, Turut P, Artin B, Charlin JF. Long-term follow-up of three-piece, looped, silicone intraocular lenses. J Cataract Refract Surg. 1996;22 Suppl 2:1259-1262.

52. Morgan-Warren PJ, Smith JA. Intraocular lens-edge design and material factors contributing to posterior-capsulotomy rates: comparing Hoya FY60aD, PY60aD, and AcrySof SN60WF. Clin Ophthalmol. 2013;7:1661-1667.

53. Nishi Y, Ikeda T, Nishi K, Mimura O. Epidemiological evaluation of YAG capsulotomy incidence for posterior capsule opacification in various intraocular lenses in Japanese eyes. Clin Ophthalmol. 2015;9:1613-1617.

54. Pradella SP, Taumer R. [Frequency of Nd:YAG capsulotomy after implantation of PMMA and silicon intraocular lenses]. Ophthalmologe. 1998;95(7):482-485.

55. Prakash P, Kasaby HE, Aggarwal RK, Humfrey S. Microincision bimanual phacoemulsification and Thinoptx implantation through a $1.70 \mathrm{~mm}$ incision. Eye (Lond). 2007;21(2):177-182.

56. Ram J, Kumar S, Sukhija J, Severia S. Nd:YAG laser capsulotomy rates following implantation of square-edged intraocular lenses: polymethyl methacrylate versus silicone versus acrylic. Can J Ophthalmol. 2009;44(2):160-164.

57. Ronbeck M, Zetterstrom C, Wejde G, Kugelberg M. Comparison of posterior capsule opacification development with 3 intraocular lens types: five-year prospective study. J Cataract Refract Surg. 2009;35(11):1935-1940.

58. Ruiz-Mesa R, Abengozar-Vela A, Aramburu A, Ruiz-Santos M. Comparison of visual outcomes after bilateral implantation of extended range of vision and trifocal intraocular lenses. Eur J Ophthalmol. 2017;27(4):460-465.

59. Schmack WH, Gerstmeyer K. Long-term results of the foldable CeeOn Edge intraocular lens. J Cataract Refract Surg. 2000;26(8):1172-1175.

60. Schriefl SM, Leydolt C, Stifter E, Menapace R. Posterior capsular opacification and Nd:YAG capsulotomy rates with the iMics Y- $60 \mathrm{H}$ and Micro AY intra-ocular lenses: 3-year results of a randomized clinical trial. Acta Ophthalmol. 2015;93(4):342-347.

61. Schriefl SM, Menapace R, Stifter E, Zaruba D, Leydolt C. Posterior capsule opacification and neodymium:YAG laser capsulotomy rates with 2 microincision intraocular lenses: Four-year results. J Cataract Refract Surg. 2015;41(5):956-963.

62. Selvam S, Khan IJ, Craig EA. Neodymium:YAG laser capsulotomy rate of microincision hydrophilic acrylic intraocular lens. J Cataract Refract Surg. 2011;37(11):2080-2081.

63. Shah VC, Russo C, Cannon R, Davidson R, Taravella MJ. Incidence of Nd:YAG capsulotomy after implantation of AcrySof multifocal and monofocal intraocular lenses: a case controlled study. J Refract Surg. 2010;26(8):565-568.

64. Spyridaki M, Hoh H. [Comparison of four MICS intraocular lenses regarding their rates of neodymium:YAG laser capsulotomy]. Klin Monbl Augenheilkd. 2010;227(3):208-214.

65. Stordahl PB, Drolsum L. A comparison of Nd:YAG capsulotomy rate in two different intraocular lenses: AcrySof and Stabibag. Acta Ophthalmol Scand. 2003;81(4):326-330.

66. Strobel J, Hunold W, Kohnen T, et al. [Highly refractive silicone lens with sharp optic edge (CeeOn Edge, Model 911): one year results of a multicenter clinical trial on performance and efficacy]. Klin Monbl Augenheilkd. 2002;219(5):358-364.

67. Sundelin K, Shams H, Stenevi U. Three-year follow-up of posterior capsule opacification with two different silicone intraocular lenses. Acta Ophthalmol Scand. 2005;83(1):11-19.

68. Sundelin K, Stenevi U. Five-year follow-up of posterior capsule opacification with two different silicone intraocular lenses. Acta Ophthalmol Scand. 2006;84(6):827-828.

69. Titiyal JS, Sinha R, Dhingra P. Posterior capsule opacification with Hydroview H60M foldable intraocular lenses. J Cataract Refract Surg. 2004;30(10):2242-2243.

70. Tran DB, Vargas V, Potvin R. Neodymium:YAG capsulotomy rates associated with femtosecond laser-assisted versus manual cataract surgery. J Cataract Refract Surg. 2016;42(10):1470-1476.

71. Vasavada AR, Raj SM, Shah A, Shah G, Vasavada V, Vasavada V. Comparison of posterior capsule opacification with hydrophobic acrylic and hydrophilic acrylic intraocular lenses. J Cataract Refract Surg. 2011;37(6):1050-1059.

72. Wejde G, Kugelberg M, Zetterstrom C. Posterior capsule opacification: comparison of 3 intraocular lenses of different materials and design. J Cataract Refract Surg. 2003;29(8):15561559.

73. Zemaitiene R, Jasinskas V. Prevention of posterior capsule opacification with 3 intraocular lens models: a prospective, randomized, long-term clinical trial. Medicina (Kaunas). 2011;47(11):595-599. 
74. Hamid A. Affect of PCO and YAG capsulotomy on the visual performance of two presbyopia-correcting IOLs. XXXIV Congress of the ESCRS; 11.09.2016, 2016; Copenhagen.

75. Johansson BR, A. Nd:YAG laser treatment incidence during 3 years after cataract surgery for 3 hydrophilic acrylic intraocular lenses, one of them with hydrophobic surface properties. XXXV Congress of the ESCRS; 10.10.2017, 2017; Lisbon.

76. Lapid-Gortzak RvdL, J.; Nieuwendaal, C.; van der Meulen, I. YAG capsulotomy rates in an angulated sharp edged hydrophilic multifocal IOL. XXXIV COngress of the ESCRS; 11.09.2016, 2016; Copenhagen.

77. Lesieur G. IOL design influence in Nd:YAG laser rates for a large series of MICS IOL implantations. XXXIV Congress of the ESCRS; 11.09.2016, 2016; Copenhagen.

78. Neri Pires GT, S.; Almas, T.; Pinheiro, L.; Vergamota, A.; Silva, J. Capsulotomy rates with 3 piece, single-piece $C$ haptics and single-piece plate intraocular lens: a 2 year minimum follow-up. Poster presented at XXXV Congress of the ESCRS; 2017; Lisbon.

79. Ursell PD, M.; Keith, M.; Majirska, K.; Ender, F.; Miglio, C.; Rabhi, S. . A multicentre, retrospective cohort study comparing the real-world incidence of Nd:YAG laser capsulotomy procedure to treat posterior capsular opacification in the first 3 years after cataract surgery among hydrophobic and hydrophilic acrylic IOLs. XXXV Congress of the ESCRS; 10.10.2017, 2017; Lisbon.

80. Vasavada S.; Vasavada VV, A.; Praveen, M.; Vasavada, V. A long-term comparison of posterior capsule opacification with hydrophobic acrylic and hydrophilic acrylic intraocular lenses. XXXIV Congress of the ESCRS; 11.09.2016, 2016; Copenhagen.

81. von Eicken J, Petermann, K., Wildgrube, M., Höh, H. Akreos MI60 - Nachstarverhalten. Poster presented at 5. Expertenforum der Firma Bausch \& Lomb. ; 11. - 13.12.2009, 2009; St. Anton/ Österreich.

82. Menapace R. Mini- and Micro-incision Cataract Surgery -A Critical Review of Current Technologies. European ophthalmic review. 2009.

83. Gonzalez-Martin-Moro J, Gonzalez-Lopez JJ, Gomez-Sanz F, Zarallo-Gallardo J, Cobo-Soriano R. [Posterior capsule opacification, capsular bag distension syndrome, and anterior capsular phimosis: A retrospective cohort study]. Arch Soc Esp Oftalmol. 2015;90(2):69-75.

84. Praveen MR, Vasavada AR, Shah GD, Shah AR, Khamar $\mathrm{BM}$, Dave KH. A prospective evaluation of posterior capsule opacification in eyes with diabetes mellitus: a case-control study. Eye (Lond). 2014;28(6):720-727.

85. Eballe AO, Ellong A, Ella GP, Dohvoma VA, Bella AL, Mvogo CE. Secondary cataract: an epidemiologic and clinical survey at the Yaounde Gynaeco-obstetric and Paediatric Hospital. Clin Ophthalmol. 2011;5:847-851.

86. Lam A, Seck CM, Gueye NN, Faye M, Pintart D. [Cataract surgery with posterior chamber lens implantation in Senegalese children less than 15 year-old]. J Fr Ophtalmol. 2001;24(6):590595.

87. Bai L, Zhang J, Chen L, Ma T, Liang HC. Comparison of posterior capsule opacification at 360-degree square edge hydrophilic and sharp edge hydrophobic acrylic intraocular lens in diabetic patients. Int J Ophthalmol. 2015;8(4):725-729.

88. Bender LE, Nimsgern C, Jose R, et al. Effect of 1-piece and 3-piece AcrySof intraocular lenses on the development of posterior capsule opacification after cataract surgery. J Cataract Refract Surg. 2004;30(4):786-789.
89. Bilge AH, Aykan U, Akin T, Unsal U. The effects of three-piece or single-piece acrylic intraocular lens (IOL) implantation on posterior capsule opacification. Eur J Ophthalmol. 2004;14(5):375-380.

90. Cavallini GM, Verdina T, Forlini M, et al. Long-term followup for bimanual microincision cataract surgery: comparison of results obtained by surgeons in training and experienced surgeons. Clin Ophthalmol. 2016;10:979-987.

91. Chang A, Behndig A, Ronbeck M, Kugelberg M. Comparison of posterior capsule opacification and glistenings with 2 hydrophobic acrylic intraocular lenses: 5- to 7-year follow-up. J Cataract Refract Surg. 2013;39(5):694-698.

92. Chang A, Kugelberg M. Posterior capsule opacification 9 years after phacoemulsification with a hydrophobic and a hydrophilic intraocular lens. Eur J Ophthalmol. 2017;27(2):164-168.

93. Daynes T, Spencer TS, Doan K, Mamalis N, Olson RJ. Threeyear clinical comparison of 3-piece AcrySof and SI-40 silicone intraocular lenses. J Cataract Refract Surg. 2002;28(7):11241129.

94. Findl O, Buehl W, Menapace R, Sacu S, Georgopoulos M, Rainer G. Long-term effect of sharp optic edges of a polymethyl methacrylate intraocular lens on posterior capsule opacification: a randomized trial. Ophthalmology. 2005;112(11):2004-2008.

95. Findl O, Hirnschall N, Nishi Y, Maurino V, Crnej A. Capsular bag performance of a hydrophobic acrylic 1-piece intraocular lens. J Cataract Refract Surg. 2015;41(1):90-97.

96. Gangwani V, Hirnschall N, Koshy J, et al. Posterior capsule opacification and capsular bag performance of a microincision intraocular lens. J Cataract Refract Surg. 2011;37(11):1988-1992.

97. Hirnschall N, Nishi Y, Crnej A, et al. Capsular bag stability and posterior capsule opacification of a plate-haptic design microincision cataract surgery intraocular lens: 3-year results of a randomised trial. Br J Ophthalmol. 2013;97(12):1565-1568.

98. Iashinskas VP, Zhemaitene R, Barzzhiukas V. [Secondary cataract and IOL type and the shape of its optic part]. Vestn Oftalmol. 2005;121(1):13-16.

99. Kahraman G, Amon M, Ferdinaro C, Nigl K, Walch M. Intraindividual comparative analysis of capsule opacification after implantation of 2 single-piece hydrophobic acrylic intraocular lenses models: Three-year follow-up. J Cataract Refract Surg. 2015;41(5):990-996.

100. Kahraman G, Schrittwieser H, Walch $M$, et al. Anterior and posterior capsular opacification with the Tecnis ZCB00 and AcrySof SA60AT IOLs: a randomised intraindividual comparison. Br J Ophthalmol. 2014;98(7):905-909.

101. Krall EM, Arlt EM, Jell G, Strohmaier C, Moussa S, Dexl AK. Prospective Randomized Intraindividual Comparison of Posterior Capsule Opacification After Implantation of an IOL With and Without Heparin Surface Modification. J Refract Surg. 2015;31(7):466-472.

102. Leydolt C, Davidovic S, Sacu S, et al. Long-term effect of 1-piece and 3-piece hydrophobic acrylic intraocular lens on posterior capsule opacification: a randomized trial. Ophthalmology. 2007;114(9):1663-1669.

103. MacLean KD, Werner L, Kramer GD, et al. Evaluation of stability and capsular bag opacification of a new foldable adjustable intraocular lens. Clin Exp Ophthalmol. 2015;43(7):648-654.

104. Mojzis P, Majerova K, Hrckova L, Pinero DP. Implantation of a diffractive trifocal intraocular lens: one-year follow-up. J 
Cataract Refract Surg. 2015;41(8):1623-1630.

105. Mylonas G, Georgopoulos M, Prinz A, Vock L, Blum RA, Schmidt-Erfurth U. Influence of a variable overall diameter hydrophilic acrylic sharp-edged single-piece intra-ocular lens on capsule opacification one year after surgery. Curr Eye Res. 2014;39(6):620-625.

106. Nanavaty MA, Spalton DJ, Gala KB, Dhital A, Boyce J. Effect of intraocular lens asphericity on posterior capsule opacification between two intraocular lenses with same acrylic material: a fellow-eye study. Acta Ophthalmol. 2012;90(2):e104-108.

107. Nanavaty MA, Spalton DJ, Gala KB, Dhital A, Boyce J. Felloweye comparison of posterior capsule opacification between 2 aspheric microincision intraocular lenses. J Cataract Refract Surg. 2013;39(5):705-711.

108. Nejima R, Miyata K, Honbou M, et al. A prospective, randomised comparison of single and three piece acrylic foldable intraocular lenses. Br J Ophthalmol. 2004;88(6):746-749.

109. Nixon DR, Woodcock MG. Pattern of posterior capsule opacification models 2 years postoperatively with 2 singlepiece acrylic intraocular lenses. J Cataract Refract Surg. 2010;36(6):929-934.

110. Oharazawa H, Suzuki H, Shibata K, et al. Quantitative analysis of posterior capsule opacification of hydrophobic acrylic intraocular lenses. J Nippon Med Sch. 2007;74(1):45-49.

111. Palomino Bautista C, Carmona Gonzalez D, Castillo Gomez A, Bescos JA. Evolution of visual performance in 250 eyes implanted with the Tecnis ZM900 multifocal IOL. Eur J Ophthalmol. 2009;19(5):762-768.

112. Pozlerova J, Nekolova J, Jiraskova N, Kadlecova J, Rozsival P. [Comparison of posterior capsule opacification in 2 types of implanted artificial intraocular lens]. Cesk Slov Oftalmol. 2007;63(1):42-46.

113. Praveen MR, Shah GD, Vasavada AR, Dave KH. The effect of single-piece hydrophobic acrylic intraocular lenses on the development of posterior capsule opacification. Am J Ophthalmol. 2015;160(3):470-478 e471.

114. Prinz A, Neumayer T, Buehl W, et al. Rotational stability and posterior capsule opacification of a plate-haptic and an open-loop-haptic intraocular lens. J Cataract Refract Surg. 2011;37(2):251-257.

115. Prinz A, Vecsei-Marlovits PV, Sonderhof D, Irsigler P, Findl O, Weingessel B. Comparison of posterior capsule opacification between a 1-piece and a 3-piece microincision intraocular lens. Br J Ophthalmol. 2013;97(1):18-22.

116. Sacu S, Findl O, Menapace R, Buehl W, Wirtitsch M. Comparison of posterior capsule opacification between the 1-piece and 3-piece Acrysof intraocular lenses: two-year results of a randomized trial. Ophthalmology. 2004;111(10):1840-1846.

117. Sacu S, Menapace R, Findl O, Kiss B, Buehl W, Georgopoulos
M. Long-term efficacy of adding a sharp posterior optic edge to a three-piece silicone intraocular lens on capsule opacification: five-year results of a randomized study. Am J Ophthalmol. 2005;139(4):696-703.

118. Spath U, Liekfeld A, Hartmann C, Pham DT. [Evaluation of posterior capsule opacification after implantation of the Akreos Disc and Akreos Fit acrylic intraocular lenses - pilot studies]. Klin Monbl Augenheilkd. 2003;220(10):695-698.

119. Toto L, Falconio G, Vecchiarino L, et al. Visual performance and biocompatibility of 2 multifocal diffractive IOLs: six-month comparative study. J Cataract Refract Surg. 2007;33(8):14191425.

120. Wang YL, Liu YZ, Wang YQ, He MG, Zhou Q, Luo LX. [Comparison of stability of acrylic intraocular lens and transparency of lens capsule using Pentacam Scheimpflug System]. Zhonghua Yan Ke Za Zhi. 2011;47(4):298-302.

121. Zemaitiene R, Jasinskas V, Auffarth GU. Influence of three-piece and single-piece designs of two sharp-edge optic hydrophobic acrylic intraocular lenses on the prevention of posterior capsule opacification: a prospective, randomised, long-term clinical trial. Br J Ophthalmol. 2007;91(5):644-648.

122. Zemaitiene R, Jasinskas V, Barzdziukas V, Auffarth GU. Prevention of posterior capsule opacification using different intraocular lenses (results of one-year clinical study). Medicina (Kaunas). 2004;40(8):721-730.

123. Kahraman GA, M.; Prager, F.; Ferdinaro, C. Intraindividual comparative analysis of capsular opacification after Tecnis ZCB00 and AcrySof SN60AT implantation during a 5-year follow-up. XXXIV Congress of the ESCRS; 11.09.2016, 2016; Copenhagen.

124. Jun JH, Kim KS, Chang SD. Nd:YAG Capsulotomy after Phacoemulsification in Vitrectomized Eyes: Effects of Pars Plana Vitrectomy on Posterior Capsule Opacification. J Ophthalmol. 2014;2014:840958.

125. Menapace R, Wirtitsch M, Findl O, Buehl W, Kriechbaum K, Sacu S. Effect of anterior capsule polishing on posterior capsule opacification and neodymium:YAG capsulotomy rates: threeyear randomized trial. J Cataract Refract Surg. 2005;31(11):20672075.

126. Westling AK, Calissendorff BM. Factors influencing the formation of posterior capsular opacities after extracapsular cataract extraction with posterior chamber lens implant. Acta Ophthalmol (Copenh). 1991;69(3):315-320.

127. Hashemi HM, S. F.; Majdi, M.; Fotouhi, A.; Khabazkhoob, M. Posterior Capsule Opacification after Cataract Surgery and its Determinants. Iranian Journal of Ophthalmology 2012;24(2):38 (c) 2012 by the Iranian Society of Ophthalmology. 2012.

128. Svancarova R, Novak J, Adamkova H. [The influence of the lens capsule mechanical polishing to the secondary cataract development]. Cesk Slov Oftalmol. 2010;66(1):21-25. 